\title{
"Nonmedical" prescription opioid use in North America: a call for priority action
}

\author{
Pauline Voon ${ }^{1}$ and Thomas Kerr ${ }^{1,2^{*}}$
}

\begin{abstract}
Nearly four years after the United States Congress heralded a "decade of pain control and research", chronic pain remains a mounting public health concern worldwide. The escalating prevalence of chronic pain in recent years has been paralleled by a rise in prescription opioid availability, misuse, and associated human and social costs. However, national monitoring surveys in the U.S. and Canada currently fail to differentiate between prescription opioid misuse for the purposes of euphoria versus pain or withdrawal management. Furthermore, there is a lack of evidence-based guidelines for pain management among high-risk individuals, and a glaring lack of education for practitioners in the areas of pain and addiction medicine. Herein we propose multiple avenues for intervention and research in order to mitigate the individual, social and structural problems related to undertreated pain and prescription opioid misuse.
\end{abstract}

Keywords: Nonmedical prescription opioid use, NMPOU, NAPOU, Not-as-prescribed opioid use, Prescription opioid misuse, Prescription drug abuse, Diversion, Pain, Substance abuse, Addiction

\section{Background}

Nearly four years after the U.S. Congress heralded a "decade of pain control and research" (for the period of 2001 to 2010) [1-3], chronic pain management remains a mounting public health concern worldwide. Globally, over 1.5 billion people suffer from chronic pain [4]. In the U.S., pain is the most common reason for seeking medical care [5-7], and the 100 million Americans suffering from chronic pain outweighs the number of Americans with diabetes, heart disease, stroke and cancer combined [8-11]. In Canada, the estimated prevalence of chronic pain is between 15-29\% [12-14]. Consequently, the cost of pain due to lost productivity and health care costs is estimated to range at least \$560-635 billion USD annually [8].

The escalating problem of chronic pain has been paralleled by a distinct rise in prescription drug misuse particularly in North America [15], with a $140.5 \%$ increase in reported prescription drug misuse among the U.S. population from 7.8 million in 1992 to 15.1 million in 2003. This represents approximately $6 \%$ of the U.S. population, which

\footnotetext{
* Correspondence: uhri-tk@cfenet.ubc.ca

'British Columbia Centre for Excellence in HIV/AIDS, St. Paul's Hospital, 608-1081 Burrard Street, V6Z 1 Y6 Vancouver, BC, Canada

${ }^{2}$ Department of Medicine, University of British Columbia, St. Paul's Hospital, 608-1081 Burrard Street, V6Z 1Y6 Vancouver, BC, Canada
}

exceeds the combined number of people in the U.S. who use cocaine, hallucinogens, inhalants, and heroin combined [16]. Canadian data, which have only recently been collected at a national level, estimate that approximately $4.8 \%$ of the general population used prescription opioids non-medically in $2009[17,18]$. As the demand for prescription opioids (POs) has risen, so has the availability of diverted POs and the prevalence of morbidities and mortalities associated with opioid use [19].

Importantly, of the $4.8 \%$ of the Canadian population that reported nonmedical PO use, only $2.3 \%$ ( $0.4 \%$ of the Canadian population) reported using POs "to get high" [17]. Thus, the remaining majority of nonmedical PO use can be attributed to factors that have been underexplored [16]. One such factor that may be fuelling the increasing demand for and availability of diverted POs is undertreated pain. One recent systematic review and meta-analysis found a $48 \%$ pooled prevalence of pain among PO misusers [20], and several studies have demonstrated a positive association between chronic pain and non-medical PO use [21,22], particularly among individuals with a history of substance misuse $[23,24]$ who are significantly more likely to receive inadequate pain management within clinical settings [25,26]. Distinctions between PO use for euphoria versus pain or withdrawal 
management must be further investigated and appropriately addressed [27], since the latter may be effectively managed with medical treatment regimes (e.g., opioid agonist therapies, directly observed treatment) that may allay PO misuse and diversion. Herein, we outline several priority recommendations that may serve to mitigate the growing health and social costs of prescription opioid misuse.

\section{Main text}

\section{Re-defining "nonmedical prescription opioid use"}

The U.S. National Survey on Drug Use and Health (NSDUH) defines nonmedical PO use (NMPOU) as "use without a prescription of the individual's own or simply for the experience or feeling the drugs cause", while the Canadian Alcohol and Drug Use Monitoring Survey (CADUMS) defines NMPOU as past-year PO use "on at least one occasion to get high [or] obtained from a prescription written for someone else, bought from someone else, or obtained from any other source" [28,29]. Alternatively, the U.S. National Epidemiologic Survey on Alcohol and Related Conditions (NESARC) defines NMPOU as use "to feel more alert, to relax or quiet nerves, to feel better, to enjoy [oneself], to get high or just to see how [POs] would work" [30]. These varying and complex definitions "rely on a mix of objective and subjective measures that are difficult to verify" [29], such as subjective PO use measures including "to feel better" (NESARC) or "simply for the experience or feeling the drugs cause" (NSDUH) combined with objective PO use measures such as the individual's source of POs [28,30]. These definitions are also problematic because they aggregate motives for and means of possessing POs into one definition and assume that PO use is a largely "nonmedical" issue despite the small proportion of PO use for euphoria [17], while the majority of PO use may be the result of medical issues such as undertreated pain or withdrawal. Thus, current definitions of NMPOU may lead to inaccurate data collection, interpretation, and counterproductive approaches such as denying POs to those with undertreated pain or withdrawal.

An improved definition may be derived from the U.S. Monitoring the Future (MTF) survey, which simply defines NMPOU as PO use "without a doctor's orders during the past 12 months" and later differentiates various motives for PO use in the survey instrument [31]. However, this definition may not capture those who have a legitimate prescription but may take their medications not as indicated (e.g., increased dose or frequency, or alternate route or indication for administration). Therefore, we suggest the term "not-as-prescribed opioid use" (NAPOU), which recognizes that opiate use may not be "nonmedical" in nature, and includes opioid use not as indicated for the individual whether by use of someone else's prescription or use of one's own prescription outside of prescribed parameters (Table 1). Within this broader definition, in-depth data collection should be undertaken to dichotomize the various motives for (e.g., euphoria versus pain versus withdrawal) and means of PO use (e.g., diverted medication from street-based markets, use of another's prescription, use of one's own prescription outside of prescribed parameters).

\section{Developing evidence-based guidelines for pain management among high-risk individuals}

Despite the high prevalence of pain among individuals with substance use disorders and psychosocial comorbidities [32,33], there is a severe lack of evidence to inform clinical guidelines for pain management among these complex populations. For instance, the American Pain Society's guidelines for chronic pain management explicitly state that their recommendations for high-risk individuals are based on "low-quality evidence" and "anecdotal experience" [34]. While these guidelines reflect the state of evidence at the time (2009), there remains a paucity of high-quality research on effective pain management approaches among substance-using populations. This is reflected by the Cochrane Collaboration's review on long-term opioid management for chronic non-cancer pain, in which the majority of studies reviewed excluded participants with a history of substance use [35]. Therefore, high-quality research on pain management for individuals with a history of substance use is urgently needed to inform evidence-based clinical practice guidelines.

\section{Educating practitioners in pain and addiction medicine}

A U.S.-wide audit found that $40 \%$ of physicians and $48 \%$ of pharmacists received formal training in identifying prescription drug abuse, yet $74 \%$ of physicians and $83 \%$ of pharmacists refused to prescribe or dispense a controlled drug due to concerns regarding addiction, diversion or misuse [16]. Deficiencies in practitioner training in pain and addiction medicine likely contribute to

Table 1 Suggested definition to replace "nonmedical prescription opioid use"

\begin{tabular}{ll}
\hline Suggested definition & Description \\
\hline Not-as-prescribed opioid use (NAPOU) & The authors suggest the term not-as-prescribed opioid use (NAPOU), which recognizes that opioid \\
& use may not be "nonmedical" in nature (e.g., undertreated pain or withdrawal), and includes opioid use \\
& not as indicated for the individual whether by the use of someone else's prescription or the use of one's \\
& own prescription outside of prescribed parameters (e.g., alternate dose, frequency, route, or indication). \\
\hline
\end{tabular}


inappropriate pain management and a growing opioid misuse epidemic [36]. For example, a lack of clinician training to inform patients about safe handling of POs may be contributing to the majority of adolescents (74\%) with unsupervised access to prescription medications [37]. Furthermore, a recent policy by the U.S. Food and Drug Administration has required manufacturing companies to develop Risk Evaluation and Mitigation Strategies that involve providing education to patients and providers on the safe use and prescribing of extendedrelease and long-acting opioids, but this policy has not been effectively translated into clinical practice [38]. Therefore, pain and addiction training should be included in core medical school and residency curricula, and pain and addiction specialists should be formally recognized and incorporated into acute and communitybased health care settings [36].

\section{Conclusions}

Prescription opioid misuse remains a growing public health concern for which urgent action is required to redefine the problem at hand, develop evidence-based guidelines, and scale up education for practitioners in pain and addiction medicine. Further investigation into the role of undertreated pain as a contributor to prescription opioid misuse affords considerable opportunity to reduce personal suffering and healthcare costs. There are multiple avenues for intervention and research, and if acted upon, much of the individual, social and structural problems related to undertreated pain and prescription opioid misuse could be meaningfully addressed.

\begin{abstract}
Abbreviations
CADUMS: Canadian Alcohol and Drug Use Monitoring Survey;

PO: Prescription opioid; MTF: Monitoring the Future; NAPOU: Not-as-prescribed opioid use; NESARC: U.S. National Epidemiologic Survey on Alcohol and Related Conditions; NMPOU: Nonmedical prescription opioid use; NSDUH: U.S. National Survey on Drug Use and Health.
\end{abstract}

\section{Competing interests}

The authors declare that they have no competing interests.

\section{Authors' contributions}

PV and TK conceptualized the commentary and drafted the manuscript together. Both authors read and approved the final manuscript.

\section{Acknowledgments \\ The authors thank Tricia Collingham and Deborah Graham for their administrative assistance.}

Received: 12 October 2013 Accepted: 26 November 2013 Published: 1 December 2013

\section{References}

1. U.S. Congress: One HUndred Sixth Congress of the United States of America. H.R. 3244, Title VI, Sec. 1603. Washington: Government Printing Office; 2004.

2. Lippe PM: The decade of pain control and research. Pain Med 2000, 1:286.

3. Gallagher RM: The pain decade and the public health. Pain Med 2000, $1: 283-285$.
4. The American Academy of Pain Medicine: AAPM Facts and Figures on Pain [Internet]. Chicago (IL): American Academy of Pain Medicine; 2013. http://www.painmed.org/PatientCenter/Facts_on_Pain.aspx.

5. U.S. Department of Health and Human Services, National Institutes of Health: Pain Management: Fact Sheet. 2010. http://report.nih.gov/ nihfactsheets/NiewFactSheet.aspx?csid=57.

6. Loeser JD, Melzack R: Pain: an overview. Lancet 1999, 353:1607-1609.

7. Vukmir RB: Drug seeking behavior. Am J Drug Alcohol Abuse 2004, 30:551-575.

8. Institute of Medicine Report from the Committee on Advancing Pain Research, Care, and Education: Relieving Pain in America, A Blueprint for Transforming Prevention, Care, Education and Research. America: The National Academies Press; 2011.

9. Heart Disease and Stroke Statistics: A Report From the American Heart Association. Circulation 2011, 123(e18-e209):20.

10. Centers for Disease Control and Prevention: National diabetes fact sheet: national estimates and general information on diabetes and prediabetes in the United States, 2011. Atlanta, GA: U.S. Department of Health and Human Services, Centers for Disease Control and Prevention; 2011.

11. Howlader N, Noone AM, Krapcho M, Neyman N, Aminou R, Waldron W, Altekruse SF, Kosary CL, Ruhl J, Tatalovich Z, Cho H, Mariotto A, Eisner MP, Lewis DR, Chen HS, Feuer EJ, Cronin KA: SEER Cancer Statistics Review. In Vintage 2009 Populations. Bethesda, MD: National Cancer Institute; 1975-2009. http://seer.cancer.gov/csr/1975_2009_pops09/, based on November 2011 SEER data submission, posted to the SEER web site, April 2012.

12. Van Den Kerkhof EG, Hopman WM, Towheed TE, Anastassiades TP, Goldstein DH: The impact of sampling and measurement on the prevalence of self-reported pain in Canada. Pain Res Manag 2003, 8:157-163.

13. Boulanger A, Clark AJ, Squire P, Cui E, Horbay GL: Chronic pain in Canada: have we improved our management of chronic noncancer pain? Pain Res Manag 2007, 12:39-47.

14. Moulin DE, Clark AJ, Speechley M, Morley-Forster PK: Chronic pain in Canada-prevalence, treatment, impact and the role of opioid analgesia. Pain Res Manag 2002, 7:179-184.

15. Fischer B, Keates A, Buhringer G, Reimer J, Rehm J: Non-medical use of prescription opioids and prescription opioid-related harms: why so markedly higher in North America compared to the rest of the world? Addiction 2013, 1. PMID:23692335 [http://www.ncbi.nlm.nih.gov/pubmed/? term=PMID\%3A+23692335]

16. The National Center on Addiction and Substance Abuse (CASA) at Columbia University: Under the Counter: The Diversion and Abuse of Controlled Prescription Drugs in the U.S. New York, NY: CASA Columbia; 2005.

17. Canada H: Canadian Alcohol and Drug Use Monitoring Survey 2009. Ottawa, Canada: Health Canada; 2010.

18. Shield KD, Jones W, Rehm J, Fischer B: Use and nonmedical use of prescription opioid analgesics in the general population of Canada and correlations with dispensing levels in 2009. Pain Res Manag 2013, 18:69-74.

19. Nosyk B, Anglin MD, Brissette S, Kerr T, Marsh DC, Schackman BR, Wood E, Montaner JS: A call for evidence-based medical treatment of opioid dependence in the United States and Canada. Health Aff 2013, 32:1462-1469.

20. Fischer B, Lusted A, Roerecke M, Taylor B, Rehm J: The prevalence of mental health and pain symptoms in general population samples reporting nonmedical use of prescription opioids: a systematic review and meta-analysis. J Pain 2012, 13:1029-1044

21. Barry DT, Goulet JL, Kerns RK, Becker WC, Gordon AJ, Justice AC, Fiellin DA: Nonmedical use of prescription opioids and pain in veterans with and without HIV. Pain 2011, 152:1133-1138.

22. Becker WC, Fiellin DA, Gallagher RM, Barth KS, Ross JT, Oslin DW: The association between chronic pain and prescription drug abuse in Veterans. Pain Med 2009, 10:531-536.

23. Novak SP, Herman-Stahl M, Flannery B, Zimmerman M: Physical pain, common psychiatric and substance use disorders, and the non-medical use of prescription analgesics in the United States. Drug Alcohol Depend 2009, 100:63-70.

24. Ives TJ, Chelminski PR, Hammett-Stabler CA, Malone RM, Perhac JS, Potisek NM, Shilliday BB, DeWalt DA, Pignone MP: Predictors of opioid misuse in patients with chronic pain: a prospective cohort study. BMC Health Serv Res 2006, 6:46

25. Baldacchino A, Gilchrist G, Fleming R, Bannister J: Guilty until proven innocent: a qualitative study of the management of chronic non-cancer 
pain among patients with a history of substance abuse. Addict Behav 2010, 35:270-272.

26. Breitbart W, Rosenfeld B, Passik S, Kaim M, Funesti-Esch J, Stein K: A comparison of pain report and adequacy of analgesic therapy in ambulatory AIDS patients with and without a history of substance abuse. Pain 1997, 72:235-243.

27. Davis WR, Johnson BD: Prescription opioid use, misuse, and diversion among street drug users in New York City. Drug Alcohol Depend 2008, 92:267-276

28. Substance abuse and mental health services administration: Results from the 2012 National Survey on Drug Use and Health: Summary of National Findings, NSDUH Series H-46, HHS Publication No. (SMA) 13-4795. Rockville, MD: Substance Abuse and Mental Health Services Administration; 2013.

29. Fischer B, Nakamura N, lalomiteanu A, Boak A, Rehm J: Assessing the prevalence of nonmedical prescription opioid use in the general Canadian population: methodological issues and questions. Can J Psychiatry 2010, 55:606-609.

30. Boyd CJ, McCabe SE: Coming to terms with the nonmedical use of prescription medications. Subst Abuse Treat Prev Policy 2008, 3:22.

31. McCabe SE, Boyd CJ, Cranford JA, Teter CJ: Motives for nonmedical use of prescription opioids among high school seniors in the United States: self-treatment and beyond. Arch Pediatr Adolesc Med 2009, 163:739-744.

32. Rosenblum A, Parrino M, Schnoll SH, Fong C, Maxwell C, Cleland CM, Magura S, Haddox JD: Prescription opioid abuse among enrollees into methadone maintenance treatment. Drug Alcohol Depend 2007, 90:64-71.

33. Sullivan MD, Edlund MJ, Zhang L, Unutzer J, Wells KB: Association between mental health disorders, problem drug use, and regular prescription opioid use. Arch Intern Med 2006, 166:2087-2093.

34. Chou R, Fanciullo GJ, Fine PG, Adler JA, Ballantyne JC, Davies P, Donovan MI, Fishbain DA, Foley KM, Fudin J, et al: Clinical guidelines for the use of chronic opioid therapy in chronic noncancer pain. J Pain 2009, 10:113-130.

35. Noble M, Treadwell JR, Tregear SJ, Coates VH, Wiffen PJ, Akafomo C, Schoelles KM: Long-term opioid management for chronic noncancer pain. Cochrane Database Syst Rev 2010, CD006605:1.

36. Wood E, Samet JH, Volkow ND: Physician education in addiction medicine. Jama 2013, 310:1673-1674.

37. Ross-Durow PL, McCabe SE, Boyd CJ: Adolescents' access to their own prescription medications in the home. J Adolesc Health 2013, 53:260-264.

38. Salinas GD, Robinson CO, Abdolrasulnia M: Primary care physician attitudes and perceptions of the impact of FDA-proposed REMS policy on prescription of extended-release and long-acting opioids. J Pain Res 2012, 5:363-369.

doi:10.1186/1747-597X-8-39

Cite this article as: Voon and Kerr: "Nonmedical" prescription opioid use in North America: a call for priority action. Substance Abuse Treatment Prevention, and Policy 2013 8:39.

\section{Submit your next manuscript to BioMed Central and take full advantage of:}

- Convenient online submission

- Thorough peer review

- No space constraints or color figure charges

- Immediate publication on acceptance

- Inclusion in PubMed, CAS, Scopus and Google Scholar

- Research which is freely available for redistribution 